\title{
Estimation of spectral reflectance of snow from IRS-1D LISS-III sensor over the Himalayan terrain
}

\author{
J Srinivasulu and A V Kulkarni \\ Marine and Water Resources Group, Space Applications Centre, Ahmedabad, 380 015, India.
}

The sensor onboard the satellite views the earth as a plain surface and consequently the satelliteobtained spectral radiances cannot represent true values over a mountainous terrain. The relative magnitudes of terrain slope and its aspect with respect to the sun's position will determine the amount of direct solar radiation incident on an undulating surface. Estimation of spectral reflectance from satellite data forms an important component in many of the snow and glacier studies. The spectral reflectance of snow is influenced by its various parameters. The changes in snowpack characteristics as a result of various metamorphic processes, with age, can cause variations in its spectral reflectances. Since, the terrain geometry also modifies the amount of reflected radiation from a rugged surface, one has to correct the estimated spectral reflectances for terrain topography so as to use them in deriving the snowpack characteristics accurately. Also, the amounts of melt runoff originating from glaciers having different slopes and orientations will not be the same. Considering these aspects, a model has been developed to estimate the terrain corrected spectral reflectances over the Himalayan terrain using the Linear Imaging Self Scanner-III data of the Indian Remote Sensing Satellite. The model computes spectral reflectances from satellitebased radiance measurements and includes the effect of the terrain topography on the incident solar radiation. The terrain slope and its aspect are generated from the digital elevation model of the region.

The analysis carried out over the Beas Basin, Himachal Pradesh, India, indicated a variation of $22 \%$ in the amount of incident solar radiation for an increase of $10^{\circ}$ in terrain slope. Further, the terrain with south-east aspect received maximum amount of solar radiation. The large differences observed between the uncorrected and terrain corrected reflectances in the shortwave infrared band (B5), which is not saturated over the snow covered region, suggest that the terrain slope and its aspect cannot be neglected in estimating the accurate spectral reflectances over the Himalayan terrain.

\section{Introduction}

Snow and glaciers cover large areas in the Himalayas. The resulting runoff from snow and glacier melt supplies water for irrigation, hydroelectric power generation, and other human enterprises. It is estimated that $30-50 \%$ of the total annual water outlay of almost all the major rivers of northern India originating in the Himalayas is provided by snow and glacier melt runoff (Agarwal et al 1983). Snow and glacier melt processes are influenced by the amount of energy reflected from them. As a result of its high visible albedo, snow reflects a much higher percentage of incoming solar short-wave radiation than snow-free surfaces. It amounts to $90 \%$ or even more for a freshly fallen snow cover and drops below $40 \%$ if the snow surface is weathered and dirty (Hall and Martinec 1985). Lower albedo will result in the higher melting rate. By increasing the reflectance of the incident solar radiation and interfering with the conduction of heat from the

Keywords. Snow; reflectance; IRS; Himalaya. 
ground, snow cover induces a cold climate (Encyclopaedia Britanica 1992). Therefore, the variations of solar radiation absorbed and reflected by the snow cover are the key factors in the estimation of snow and glacier melt runoff and in understanding the climatic role of snow and glacier regions.

Snowpack parameters such as grain size, liquid water content and amount of contamination influence its reflectance in various spectral regions (O'Brien and Munis 1975; Wiscombe and Warren 1980; Warren and Wiscombe 1980; Kulkarni 1986). In the visible wavelengths snow albedo is sensitive to contamination but not to grain size. In the near-infrared snow albedo is sensitive to grain size, but not to contamination (Dozier et al 1988). Therefore, the changes in these snowpack parameters, as snow changes from one metamorphic state to the other, can be assessed from the variations observed in its spectral albedo or vice versa. Such studies are useful in the assessment of possible potential runoff from snow and glaciated regions and also in avalanche forecasting. Reflectance also forms an important input in estimating Normalized Difference Snow Index (NDSI), which is useful for snow identification under the conditions of cloud cover and mountain shadow (Kulkarni et al 2002).

Much work has been done to estimate spectral reflectance using the Landsat data (Dozier 1984; Hall et al 1988). The formulations were based on the fact that the satellite data depict the earth as a flat surface and thus the satellite measurements of spectral radiances obtained are valid only for plain surfaces on the earth. However, in mountain regions like the Himalayas, the terrain has a variety of undulations and orientations. The amount of direct solar radiation incident on an inclined surface varies as the cosine of the local illumination angle, which is a function of the terrain slope and its aspect and as well as the solar zenith and azimuth angles. Models have been developed to estimate the direct radiation income of slopes in any latitude by using the terrain geometry and the sun's declination (Robinson 1966; Garnier and Ohmura 1968; Tiellet et al 1982). Such models have been applied over the mountain regions to estimate spectral reflectances in the Landsat Thematic Mapper bands (Dozier 1989; Duguay and LeDrew 1992; Hall et al 1995).

This paper presents a model to estimate spectral reflectance for the Himalayan terrain using the LISS-III data from Indian Remote Sensing Satellites. The various parameters used as input to this model are: mean solar exo-atmospheric spectral irradiances in the sensor bands, digital elevation information, solar declination, mean earth-sun distance on a Julian day, and the calibration parame- ters of the sensor, such as maximum and minimum radiances in the sensor bands. The terrain topography parameters, viz., terrain slope and aspect are derived from the digital elevation information of the terrain. The local illumination angle for each pixel, which determines the amount of direct solar radiation incident on a sloped surface, is computed using both the sun and terrain geometry. The model is applied over the Manali region of the Beas basin in Himachal Pradesh (India), using the IRS-1D LISS-III data to estimate terrain corrected reflectances.

\section{Model description}

One of the important concepts in the determination of various objects through remote sensing is that different objects reflect energy differently in various parts of the electromagnetic spectrum. On a satellite image, this reflected energy is normally represented as a binary value, known as digital number (DN) and depends on the calibration parameters and radiometric resolution of the sensor. Whereas the actual reflectance from an object, which is based on fraction of incoming solar radiation, depends on various parameters, such as, solar elevation, surface slope and its orientation, surface anisotropy, and atmospheric constituents. Optimum detection of object requires that data be expressed in physical units, such as radiance or reflectance. Therefore, understanding of the spectral reflectance characteristics is necessary for proper interpretation of satellite images.

Estimation of reflectance from digital satellite data involves conversion of digital numbers into the radiance values, known as sensor calibration, and then estimation of reflectance from these radiance values. The various parameters needed for estimating spectral reflectances are maximum and minimum radiances and mean solar exo-atmospheric spectral irradiances in the satellite sensor bands, satellite data acquisition time, solar declination, solar zenith and solar azimuth angles, mean earthsun distance, and terrain slope and its aspect.

\subsection{Computation of spectral reflectance}

Reflectance is the ratio of the upwelling radiance from the surface to the equivalent solar radiance incident on the surface. Satellite sensors measure the upwelling radiance above the earth's atmosphere, and the received signals from various targets are represented on an image in terms of digital numbers. Spectral radiance from a pixel in each band, denoted by $L_{\lambda}$ with the units of 
Table 1. Minimum and maximum radiances for the IRS-1D LISS-III sensor (Feb. 8 2001, Path: 95, Row: 48).

\begin{tabular}{cccr}
\hline Band & $\begin{array}{c}\text { Wavelength } \\
\text { range }(\mathrm{nm})\end{array}$ & $\begin{array}{c}L \text { min } \\
(\mathrm{mW} \mathrm{cm} \\
\left.\mathrm{sr}^{-1} \mu \mathrm{m}^{-1}\right)\end{array}$ & $\begin{array}{c}L \max \\
(\mathrm{mW} \mathrm{cm} \\
\left.\mathrm{sr}^{-1} \mu \mathrm{m}^{-1}\right)\end{array}$ \\
\hline B2 & $520-590$ & 0.0 & 14.8005 \\
\hline B3 & $620-680$ & 0.0 & 15.6644 \\
\hline B4 & $770-860$ & 0.0 & 16.4523 \\
\hline B5 & $1550-1700$ & 0.0 & 2.4381 \\
\hline
\end{tabular}

Table 2. Mean solar exo-atmospheric spectral irradiances in the IRS-1D LISS-III bands.

\begin{tabular}{lcc}
\hline Band & $\begin{array}{c}\text { Wavelength } \\
\text { range }(\mathrm{nm})\end{array}$ & $\begin{array}{c}\text { Mean solar } \\
\text { exo-atmospheric, } \\
E_{\mathrm{sun} \lambda}\left(\mathrm{mW} \mathrm{cm} \mathrm{cm}^{-2}\right)\end{array}$ \\
\hline B2 & $520-590$ & 185.216 \\
\hline B3 & $620-680$ & 157.731 \\
\hline B4 & $770-860$ & 109.666 \\
\hline B5 & $1550-1700$ & 24.062 \\
\hline
\end{tabular}

$\mathrm{mW} \mathrm{cm}^{-2} \mathrm{sr}^{-1} \mu \mathrm{m}^{-1}$, is proportional to its digital number (DN) and can be derived by using the $\operatorname{minimum}\left(L \min _{\lambda}\right)$ and maximum $\left(L \max _{\lambda}\right)$ radiance values of a sensor band (Markham and Barker 1986). One set of $L \min _{\lambda}$ and $L \max _{\lambda}$ exists for each gain state of a sensor band and these values will change slowly over time as the detectors loose responsivity. $L$ max and $L$ min for each band, corresponding to a current gain setting of a satellite sensor, can be obtained from the satellite header information. The typical values for the LISS-III sensor of IRS-1D satellite, dated February 8th, 2001, are given in table 1. Spectral reflectance of a pixel in each band can be estimated from the computed spectral radiance and the mean solar exo-atmospheric spectral irradiance $\left(E_{\operatorname{sun} \lambda}, \mathrm{mW} \mathrm{cm}^{-2} \mu \mathrm{m}^{-1}\right)$, by using the equation given by Markham and Barker (1986 and 1987). The computed values of mean solar exoatmospheric spectral irradiances for LISS-III channels of IRS-1D satellite are given in table 2 (Pandya et al 2002).

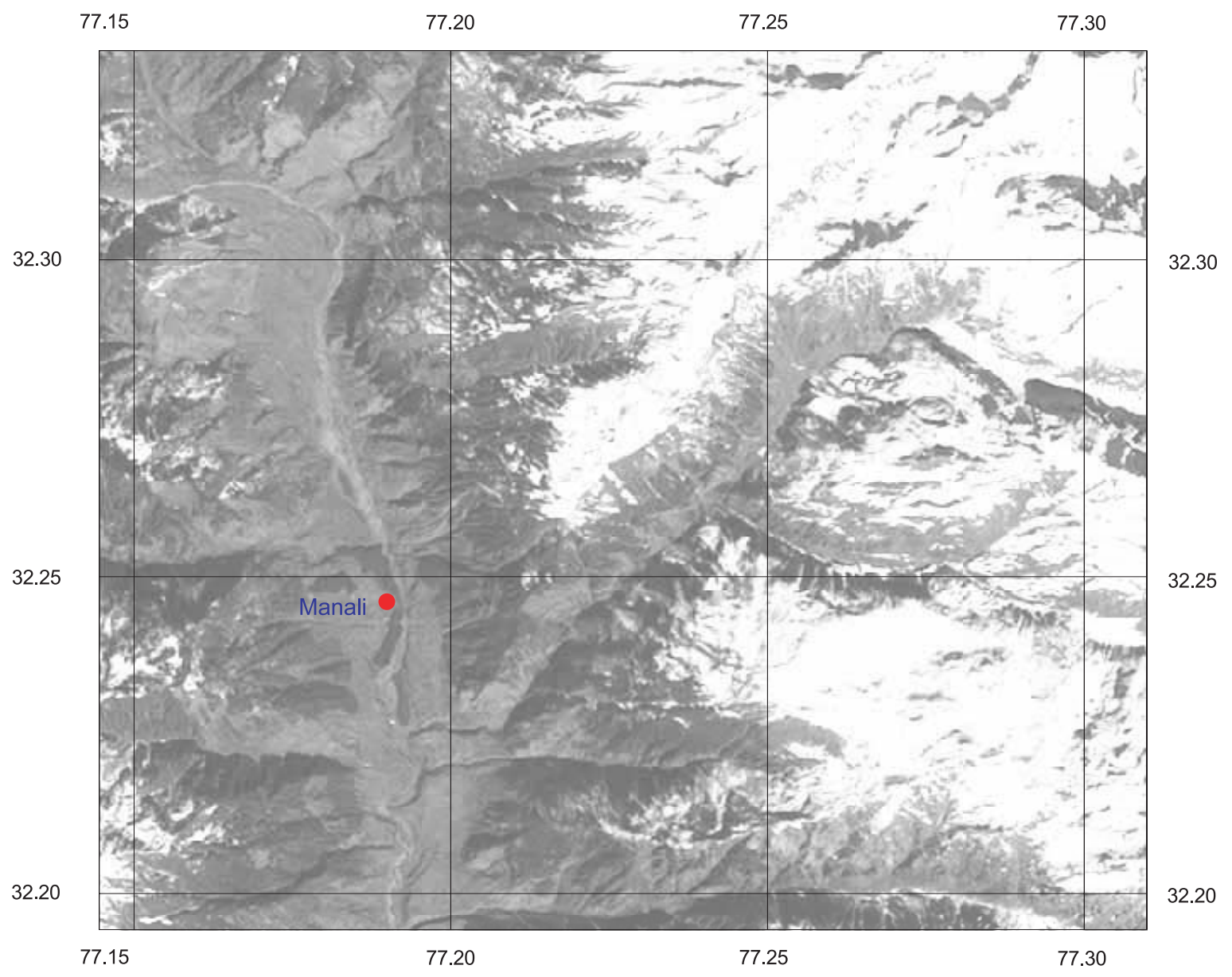

Figure 1. FCC (3:2:1) image obtained by IRS-1D LISS-III, dated February 8th, 2001, over Manali region, Beas basin (H.P.), India. 

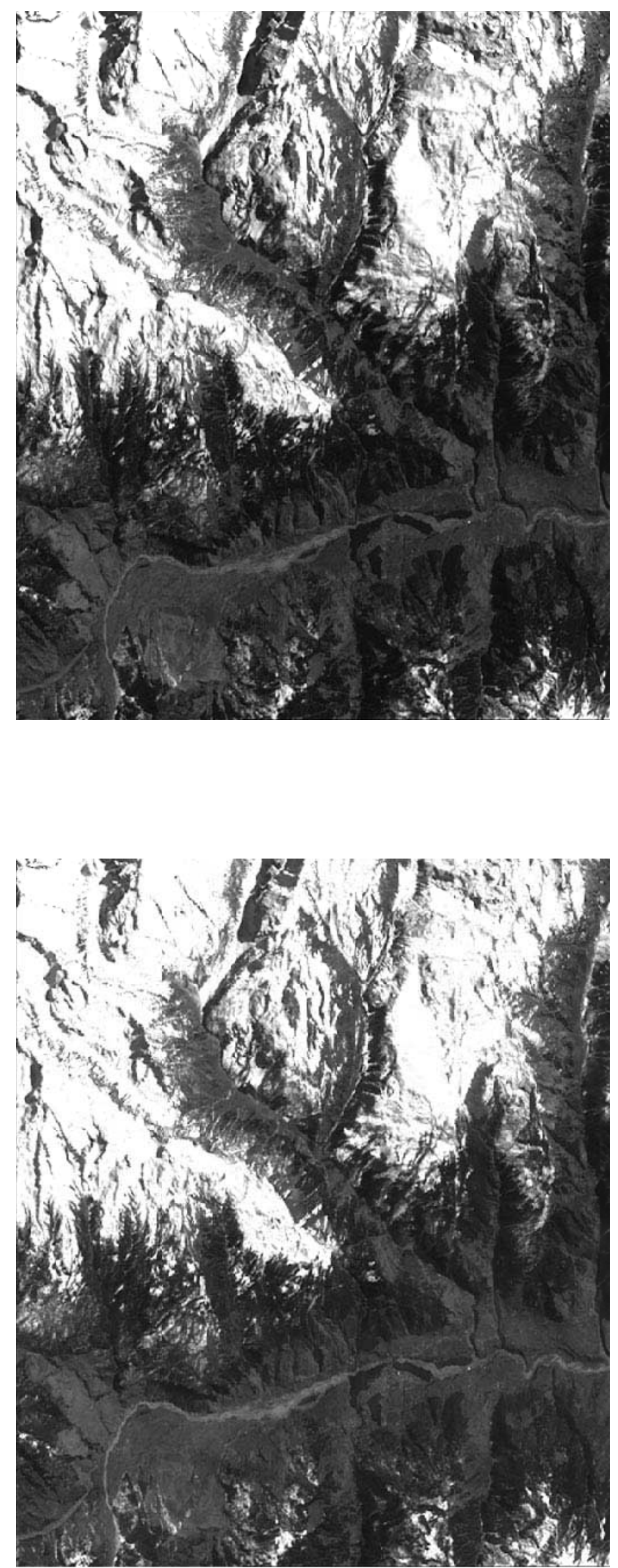

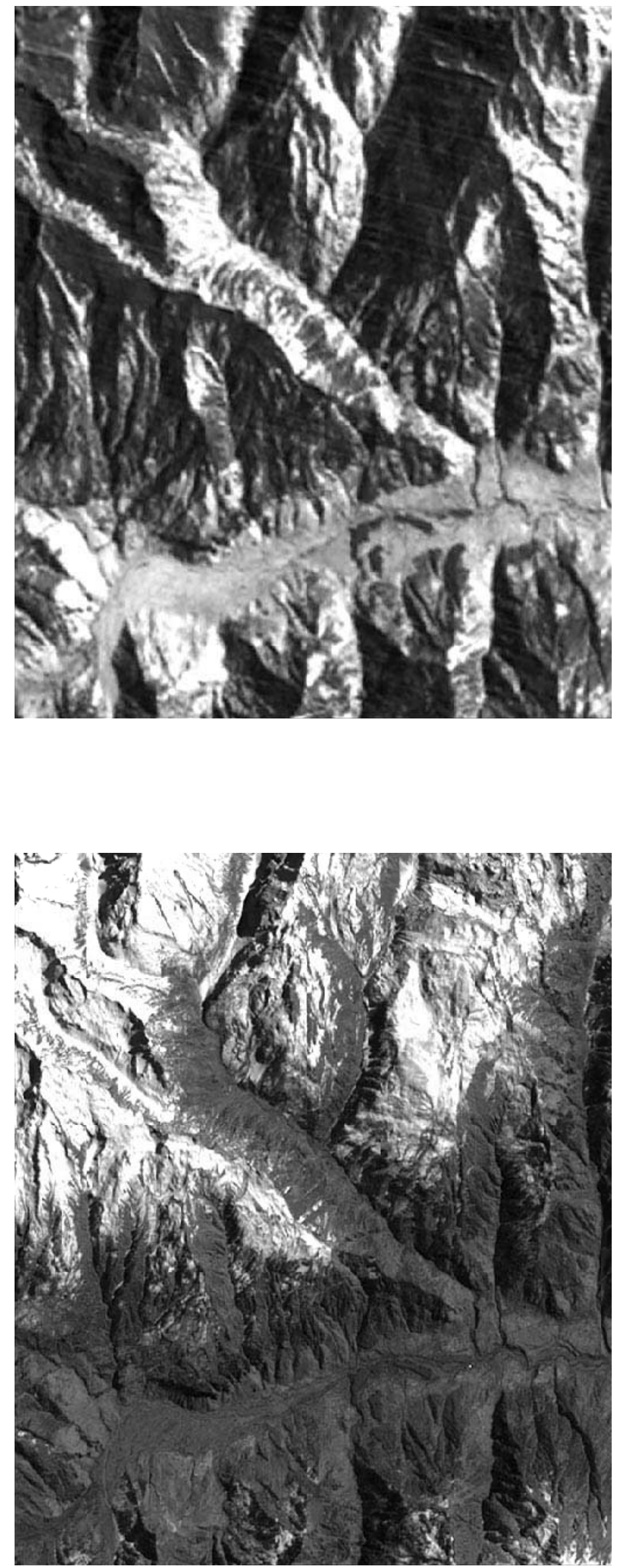


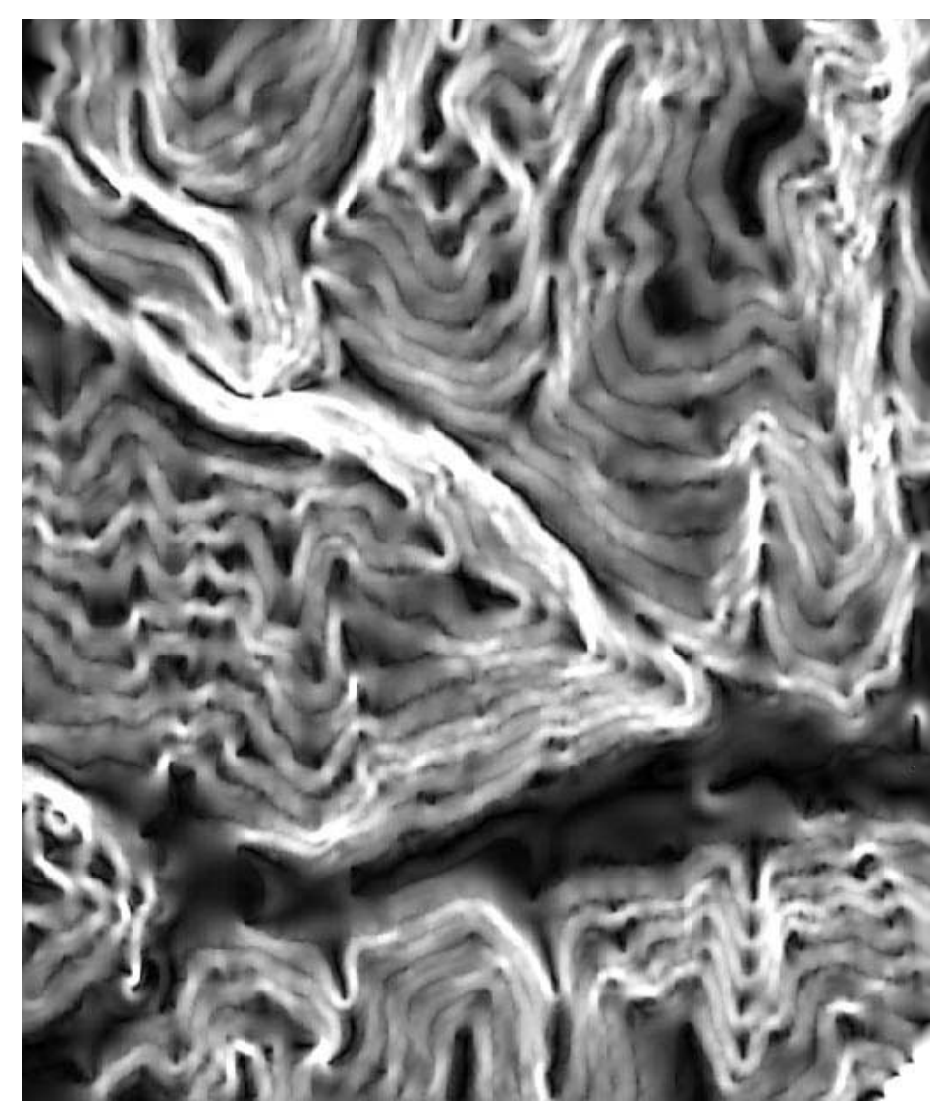

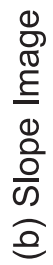

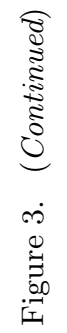

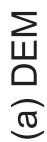




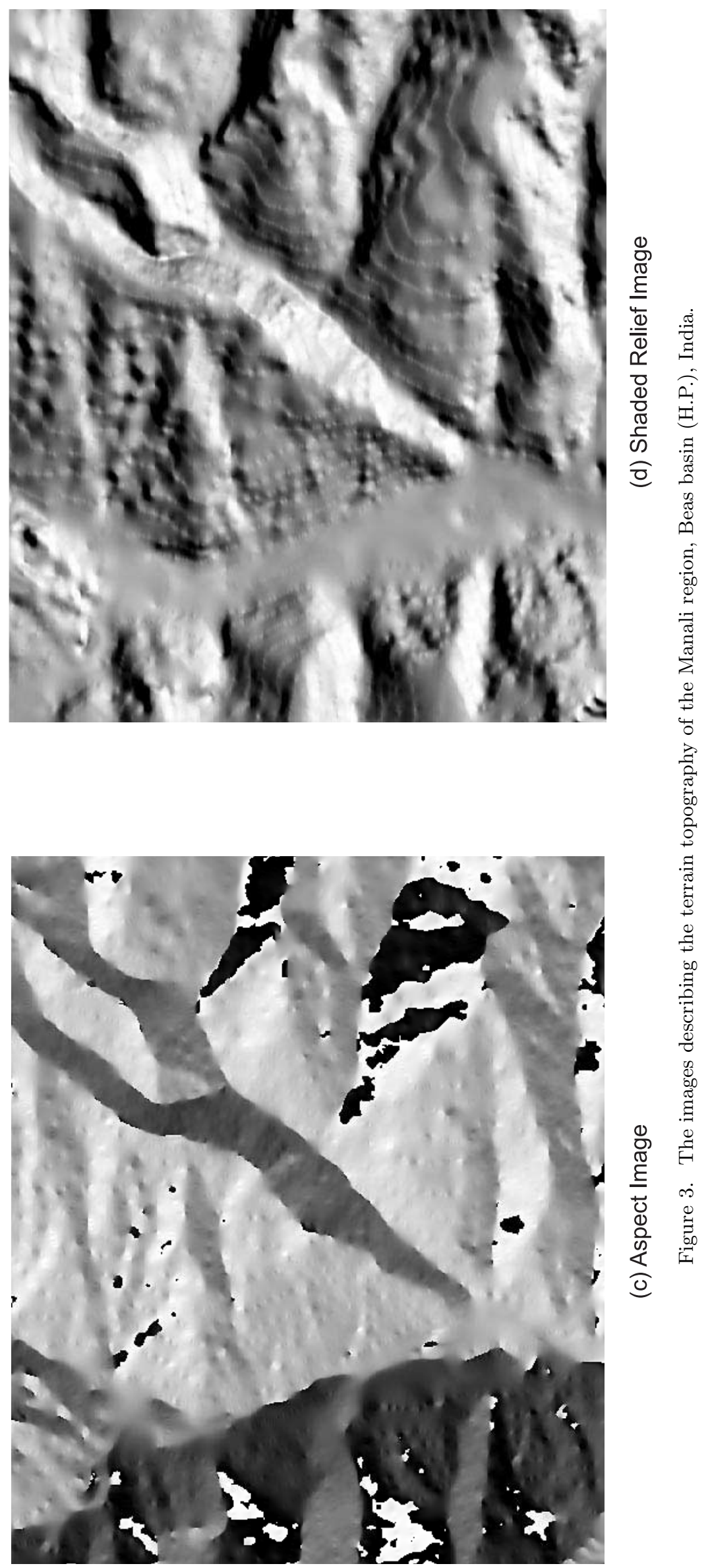




\subsection{Estimation of terrain corrected reflectance}

The Markham and Barker equation for computing reflectance from a flat area cannot be valid for the Himalayan region where the terrain is highly undulating. To estimate reflectance from a rugged terrain, cosine of the local illumination angle, not the cosine of solar zenith angle, has to be used as given below:

$$
\rho_{\lambda}=\frac{\pi L_{\lambda} d^{2}}{E_{\mathrm{sun} \lambda} \cos \theta_{i}},
$$

where $d$ is the mean earth-sun distance on a Julian day (AU), and $\theta_{i}$ is the local illumination angle (degree), the angle between the sun's rays and the surface normal and is calculated by using the relation given by Robinson (1966).

\section{Application of the model in the Himalayan region}

The model has been used to estimate the spectral reflectances in the IRS-1D LISS-III bands covering the Manali region in the Beas Basin of the Indian Himalayas (figure 1). The digital numbers were converted into radiances by using the conversion formula given by Markham and Barker (1986). The spectral reflectances were estimated in the LISSIII bands without considering the effect of terrain geometry (figure 2). It is found that the vegetation cover has low reflectance in red band, B3, and high reflectance in near-infrared band, B4, while the soil has increasing reflectance from B2 to B5. Although snow shows decreasing reflectance from B2 to B5, because of the sensor saturation the estimated reflectances do not represent the true numbers. The saturation radiance in each band is expressed as a percentage of the solar constant (table 3). If the product of the estimated reflectance and the cosine of the solar zenith angle exceeds the saturation radiance in a band then saturation occurs (Dozier 1985). The analysis using the IRS-1D LISSIII data over the Beas Basin, on February 8th,
2001, indicated that saturation occurred in all the bands except B5 where the per cent saturation is much more than the maximum value of the product $\left(\rho_{\lambda} \cos \theta_{s}\right)$ observed in that band. It was found that 43700 snow pixels in B2 (13.51\%), 34750 pixels in B3 (10.74\%), and 8925 pixels in B4 $(2.76 \%)$ are saturated in this region.

\subsection{The effect of terrain topography on direct solar irradiance}

The digital elevation model (figure 3a) was used to compute the terrain geometry parameters, i.e., its slope (figure 3b), and aspect (figure 3c). The elevation in this region varies between 1700 and $4800 \mathrm{~m}$. The maximum slope observed in the region is $84.05^{\circ}$ with a mean terrain slope of $25.34^{\circ}$. The terrain has a southern trend with an average aspect of $205^{\circ}$. The solar geometry parameters viz., solar zenith angle and solar azimuth angle, were computed for each pixel using the standard equations available in the literature (Kasten 1962; Tiellet et al 1982). Both the terrain as well as solar geometry parameters were then used to derive the cosine of the local illumination angle for each pixel by using the equation given by Tiellet et al (1982). The resulting image, also known as the shadedrelief image (figure 3d), describes the relative orientation of each pixel with reference to the position of the sun. Thus, the cosine of the local illumination angle of a pixel determines the amount of solar radiation received by it. The pixels with cosine of the illumination angle less than or equal to zero will be under the shadow, i.e., they do not receive the direct solar radiation.

The amount of direct solar radiation incident on a slope, given by $\left(E_{\operatorname{sun} \lambda} \cos \theta_{i} / \pi\right)$, was estimated in the wavelength range of LISS-III B2 band. The mean solar zenith angle of $49.21^{\circ}$ and the mean solar azimuth angle of $162.62^{\circ}$, which correspond to the IRS-1D LISS-III data on 8th February 2001 over the study region, were used in the computations. The effect of atmospheric transmission was not considered in this analysis. Figure 4 describes the effect of terrain slope and its aspect on the

Table 3. Saturation characteristics of IRS-1D LISS-III bands.

\begin{tabular}{|c|c|c|c|c|}
\hline Band & $\begin{array}{l}\text { Wavelength range } \\
\qquad(\mathrm{nm})\end{array}$ & $\begin{array}{c}\text { Mean solar exo- } \\
\text { atmospheric irradiance } \\
E_{\mathrm{sun} \lambda} \\
\left(\mathrm{mW} \mathrm{cm}{ }^{-2} \mu \mathrm{m}^{-1}\right)\end{array}$ & $\begin{array}{c}\text { Saturation radiance } \\
\quad L \max \\
\left(\mathrm{mW} \mathrm{cm}^{-2} \mathrm{sr}^{-1} \mu \mathrm{m}^{-1}\right)\end{array}$ & $\begin{array}{c}\text { Per cent saturation } \\
(L \max * 100) /\left(E_{\operatorname{sun} \lambda} / \pi\right) \\
(\%)\end{array}$ \\
\hline $\mathrm{B} 2$ & $520-590$ & 185.216 & 14.8005 & 25.1 \\
\hline B3 & $620-680$ & 157.731 & 15.6644 & 31.2 \\
\hline B4 & $770-860$ & 109.666 & 16.4523 & 47.1 \\
\hline B5 & $1550-1700$ & 24.062 & 2.4381 & 31.8 \\
\hline
\end{tabular}




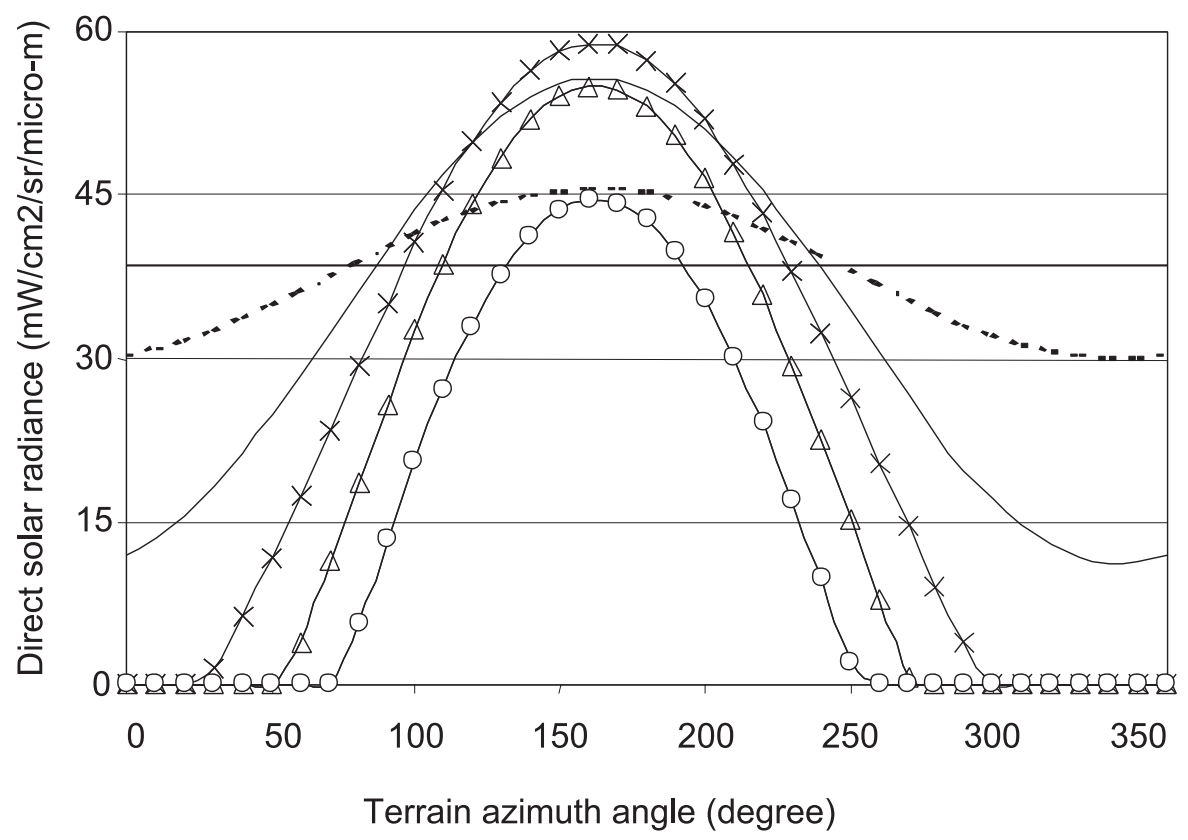

Terrain slope (degree)

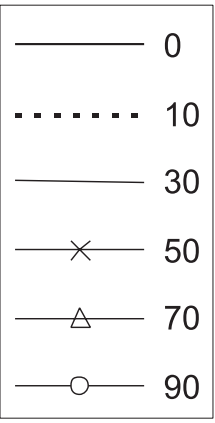

Figure 4. The direct solar radiation income of a sloped terrain (Beas basin) calculated in the wavelength range of IRS-1D LISS-III B2, on February 8th, 2001.

amount of incident direct solar radiation. It can be observed that all the curves are symmetric with respect to the azimuth angle of about $160^{\circ}$, which coincides with the mean solar azimuth angle $\left(162.62^{\circ}\right)$. The maximum value of incident solar radiation corresponds to the terrain slope angle of about $50^{\circ}$, which equals the mean solar zenith angle of the region. This implies that the surfaces that are normal to the incident solar beam and have the aspect angle equal to the azimuth angle of the sun will receive the maximum amount of direct solar radiation.

It is deduced from figure 4 that an increase of even $10^{\circ}$ in terrain slope, keeping the terrain azimuth angle as constant, can cause a variation of as much as $22 \%$ in the incident direct solar radiation values. It is observed that for the solar geometry corresponding to the LISS-III pass over this region, the terrain slopes with south-east aspect received maximum amount of solar radiation, followed by the slopes with south-west, north-east, and north-west aspects. Further, the north-west oriented slopes received direct solar radiation only when their slopes were less than $50^{\circ}$, i.e., these slopes were under shadow for slope angles greater than $50^{\circ}$. Thus, both terrain slope and its aspect are the two critical parameters in determining the amount of direct solar radiation incident on a rugged mountainous terrain.

Since B2, B3, and B4 bands of LISS-III sensor saturate over a snow-covered region, the effect of terrain topography on the estimates of satellitebased spectral reflectance can be better illustrated using the LISS-III B5 data, which is not saturated over the snow-covered region. Reflectance in the LISS-III B5 band, uncorrected for terrain geometry, was estimated using the Markham and Barker (1986) equation (figure 5a), while the terrain geometry corrected reflectance was estimated using the equation (1) (figure 5b). Observation of statistics of both the reflectance images indicate a maximum value of $38.44 \%$ in the uncorrected reflectance image, and in the terrain corrected reflectance image the maximum value observed is $57.67 \%$. Typical reflectance values for the randomly selected snow and non-snow targets, having different slope and aspect angles, are tabulated in table 4. Significant differences were observed in the pixel reflectance values obtained before and after terrain correction, which indicates that terrain geometry can substantially modify the satellitebased reflectance estimates.

Table 4. Typical reflectance values for the randomly selected snow and non-snow targets estimated in the IRS-1D LISS-III band B5 over the Manali region, Beas Basin (H.P.), India.

\begin{tabular}{lccc}
\hline & \multicolumn{2}{c}{ Reflectance $(\%)$} & \\
\cline { 2 - 3 } Target & Uncorrected & $\begin{array}{c}\text { Terrain } \\
\text { corrected }\end{array}$ & $\begin{array}{c}\text { Per cent } \\
\text { change }(\%)\end{array}$ \\
\hline Snow & 6.9 & 10.3 & +449.7 \\
\hline Snow & 8.0 & 6.8 & -15.2 \\
\hline Non-snow & 8.8 & 9.6 & +9.4 \\
\hline Non-snow & 33.3 & 22.9 & -31.1 \\
\hline
\end{tabular}




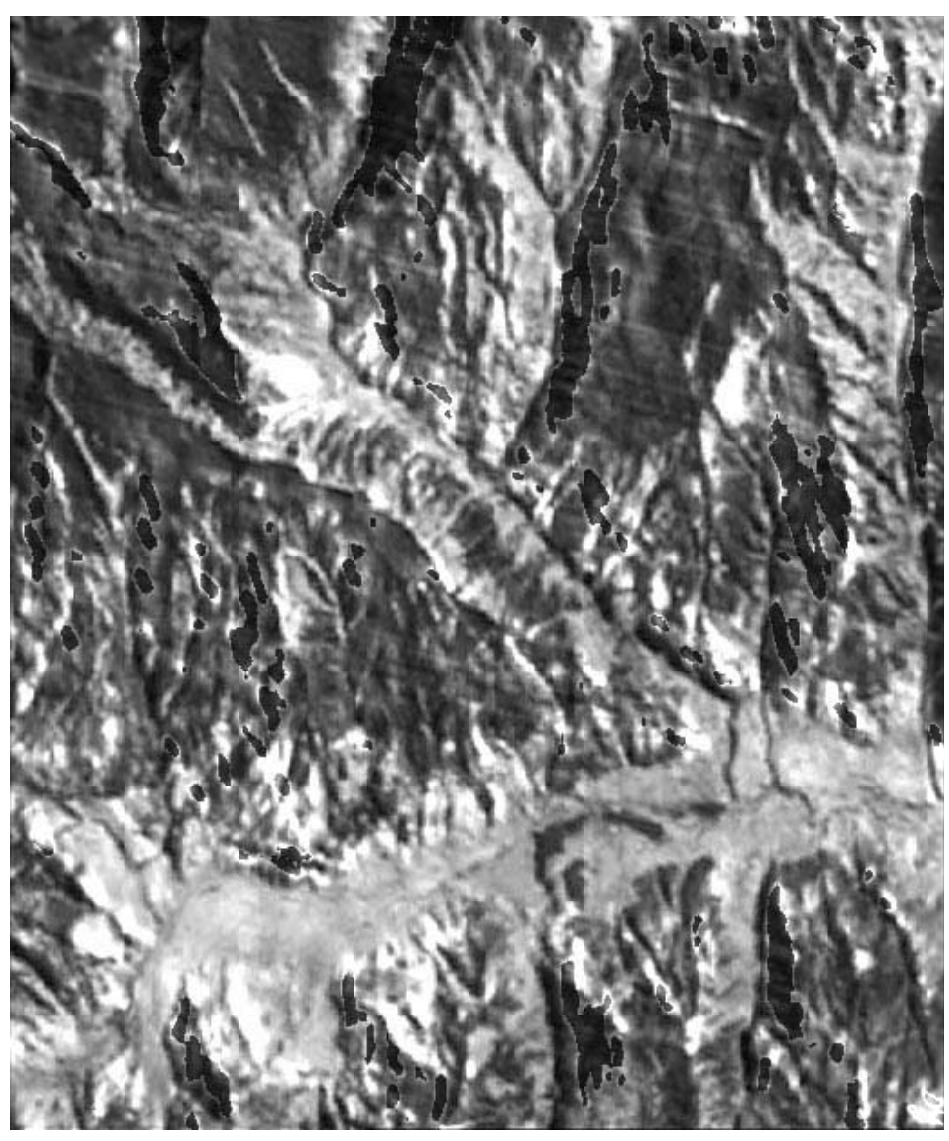

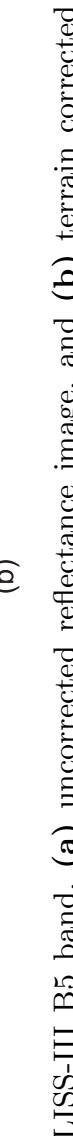

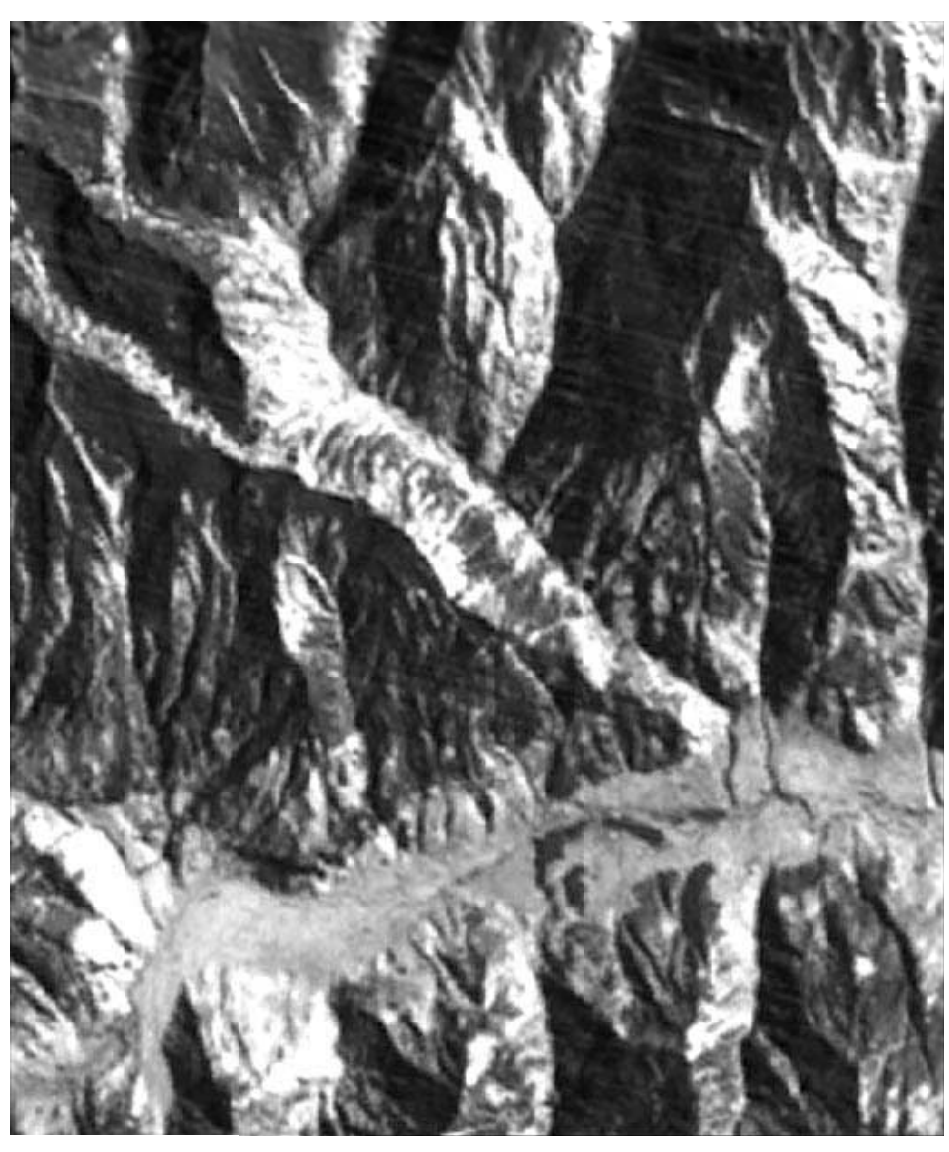

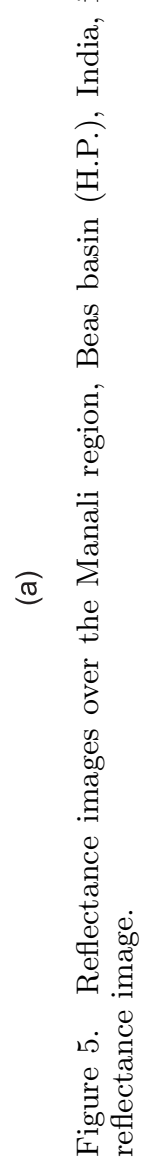


Shadow regions can be seen clearly in the terrain corrected reflectance image, which are separated from the adjacent terrain by distinct bright boundaries (figure 5b). Dozier (1985) also observes bright areas in the terrain corrected Landsat TM image, which, he attributes, are due to mis-registration with the elevation grid. As pointed out in the previous paragraphs, shadow regions, as delineated in figure 5(b), do not receive the direct solar radiation. Therefore, computation of reflectance from targets in the shadow regions requires the use of diffuse spectral irradiance rather than the direct spectral irradiance. This requires field measurements of diffuse irradiance in the wavelength range of satellite sensor bands. Further, one may also need to consider the irradiance component from the adjacent terrain, which is common in snowbound rugged terrain, for improving the accuracy of spectral reflectance estimates. These aspects will be incorporated in the future reflectance studies.

\section{Conclusions}

The effect of terrain topography on the incident solar radiation over the rugged Himalayan terrain was illustrated by using the IRS-1D LISSIII data. The model was used to estimate terrain corrected spectral reflectances by using the DEM derived terrain geometry parameters and the satellite header data. The visible and the near infrared bands of IRS-1D LISS-III sensor were saturated over the snow-covered region. The large differences observed between the uncorrected and terrain corrected reflectances in the SWIR band (B5) suggest that the terrain slope and its aspect substantially modifies the reflectance. The analysis in the Manali region indicates that an increase of even $10^{\circ}$ in terrain slope can cause a variation in the incident solar radiation by as much as $22 \%$. It was found that the slopes with south-east (SE) aspect received maximum solar radiation followed by slopes with south-west (SW), north-east (NE) and north-west (NW) aspect. Such studies are very useful in glacier mass balance studies and in estimating the relative contributions of various glaciers, having different slopes and orientations, to the total runoff from a basin.

\section{Acknowledgements}

The authors would like to thank Dr. Shailesh Nayak, Group Director, Marine and Water Resources Group, Space Applications Centre for suggestions and comments during the investigation.

\section{References}

Agarwal K G, Kumar V and Das T 1983 Melt runoff for a subcatchment of Beas basin; In: Proceedings of the First National Symposium on Seasonal Snow Cover, 43 pp., New Delhi, India, April 28-30

Dozier J 1984 Snow reflectance from Landsat-4 Thematic Mapper; IEEE Transactions on Geoscience and Remote Sensing, GE-22(3) 323-328

Dozier J 1985 Spectral signature of snow in visible and nearinfrared wavelengths; In: Proceedings of the Third International Colloquium on Spectral Signatures of Objects in Remote Sensing, ESA SP-247, pp. 437-442, Les Arcs, France, Dec 16-20

Dozier J, Davis R E, Chang A T C and Brown K 1988 The spectral bi-directional reflectance of snow; In: Proceedings of the Fourth International Colloquium on Spectral Signatures of Objects in Remote Sensing, ESA-SP-287, pp. 87-92, Aussois, France, Jan 1822

Duguay C G and LeDrew E F 1992 Estimating surface reflectance and albedo from Landsat-Thematic Mapper over rugged terrain; Photogrammetric Engineering 8 Remote Sensing 5 551-558

Encyclopaedia Britanica, Micropaedia, 10 912-913 The University of Chicago, 1992

Garnier B J and Ohmura A 1968 A method of calculating the direct shortwave radiation income of slopes; J. Appl. Meteorol. 7 796-800

Hall D K and Martinec J 1985 Remote Sensing of ice and snow (New York: Chapman and Hall)

Hall D K, Chang A T C and Siddalingaiah H, 1988 Reflectances of glaciers as calculated using Landsat-5 Thematic Mapper data; Remote Sensing of Environment 25 311-321

Hall D K, Riggs G A and Salomonson V 1995 Development of methods for mapping global snow cover using Moderate Resolution Imaging Spectroradiometer Data; Remote Sensing of Environment 54 127140

Kasten F 1962 Table of solar altitudes for geographical latitudes $\pm 77^{\circ} 10^{\prime}$; CRREL Special Report $5 \%$, U.S. Army Corps of Engineers, Hanover, New Hampshire

Kulkarni A V 1986 A field study of the visible and near-infrared spectral reflectance and attenuation of solar radiation by snow, M.Sc. Thesis, Department of Geography, McGill University, Montreal, Canada, 109

Kulkarni A V, Srinivasulu J, Manjul S S and Mathur P 2002 Field based spectral reflectance studies to develop NDSI method for snow cover monitoring; J. Indian Society of Remote Sensing 30(1\&2) 73-80

Markham B L and Barker J L 1986 Landsat MSS and TM post-calibration dynamic ranges, exoatmospheric reflectances and at-satellite temperatures; In: EOSAT Technical Notes, No. 1, 3-8

Markham B L and Barker J L 1987 Thematic Mapper bandpass solar exoatmospheric irradiances; Int. J. Remote Sensing 8(3) 517-523

O'Brien H W and Munis R H 1975 Red and near-infrared reflectance of snow; CRREL Research Report 332, pp. 18, U.S. Army Cold Regions Research and Engineering Laboratory, Hanover, New Hampshire

Pandya M R, Singh R P, Murali K R, Babu P N, Kiran Kumar A S and Dadhwal V K 2002 Bandpass solar exo-atmospheric irradiance and Rayleigh optical thickness of sensors onboard Indian Remote Sensing Satellites-1B, 1C, 1D, and P4; IEEE Transactions on 
Geoscience and Remote Sensing, Vol. 3, March 2002 (in press).

Robinson N 1966 Solar Radiation (New York: Elsevier)

Tiellet P M, Guindon B and Goodenough D G 1982 On the slope-aspect correction of multispectral scanner data; Canadian J. of Remote Sensing 8(2) 84-106
Warren S G and Wiscombe W J, 1980 A model for the spectral albedo of snow, II, Snow containing atmospheric aerosols; J. Atmos. Sci. 37(12) 2734-2745

Wiscombe W J and Warren S G 1980 A model for the spectral albedo of snow, I, Pure snow; J. Atmos. Sci. 37(12) $2712-2733$

MS received 24 March 2003; revised 4 September 2003 